\title{
Considering the lumbosacral geometry as a functional matrix predicting the development of spine derangement and low back pain.
}

\author{
Chike Patrick Anibeze ${ }^{1}$, Gilbert C Ossi ${ }^{2}$, Chinenye O Ani ${ }^{3}$, Uchenna Kenneth Ezemagu ${ }^{*}$ \\ ${ }^{1}$ Department of Anatomy, Enugu State University of Science and Technology, Nigeria \\ ${ }^{2}$ Department of Radiology, National Orthopedic Hospital, Enugu, Nigeria \\ ${ }^{3}$ Department of Radiology, Enugu State University Teaching Hospital, Nigeria \\ ${ }^{4}$ Department of Anatomy, Alex Ekwueme Federal University Ndufu Alike Ikwo, Ebonyi State Nigeria
}

\begin{abstract}
Purpose: The contribution of lumbosacral geometry to the development of spine anomalies is unclear. This study tested whether sacral base angle (SBA), lumbar gravity line position (GL) and patient height (HP) are associated with low back pain (LBP) and spondylolisthesis. The study aimed to determine the validity of SBA and GL in radiological evaluation and as factors that predisposes the lumbosacraAl junction (LSJ) to certain derangements.

Materials and Methods: The prospective study involved 488 adult patients. Patients with non-injury related LBP (84) and those (46) without $L B P$; age range: 16-80 years were included. The remaining patients (358) with injury-related LBP were excluded. Digital images of antero-posterior and lateral views of the lumbosacral spine of the patients were blindly examined by two consultant radiologists. Pathologies were identified and classified according to age and sex. SBA and GL were determined using Ferguson's methods and height was measured using a health scale.

Results: SBA (odds ratio: $1.045, \mathrm{P}<0.05)$ and $\mathrm{GL}$ (odds ratio: $0.265, \mathrm{P}<0.05$ ) were significant factors predicting the development of LBP and spondylolisthesis, respectively. GL was found to be related to SBA $(r=-0.409, p<0.01)$. Occurrence of LBP did not depend on age, sex, or HP.

Discussion and Conclusion: SBA and GL are factors that should be considered when diagnosing noninjury related LBP and spondylolisthesis, respectively, as well as for correction of LSJ geometric distortion and when considering activities associated with transfer of large weights at the LSJ.
\end{abstract}

Keywords: Back pain, Body height, Ferguson's methods, Lumbosacral region, Spine, Stress.

Accepted on May 15, 2019

\section{Introduction}

In chiropractics and orthopedics, the roles of shapes, lines, curves and angles formed by the alignment of different parts of lumbosacral structures in stress and spine derangements remain unclear. In mechanics, the center of gravity is where the whole weight of an object seems to act as proved by some elementary geometry [1,2]. Ardently, we queried the significance of the lumbosacral angle and lumbar gravity line position in spondylolisthesis and the reports of some authors $[3,4]$ that they determine the stability of lumbosacral region. Although it is clear that mechanical forces are involved in initiating disc degeneration, the signaling pathways initiated by mechanical stress and thresholds for these responses require further elucidation [5].

While the biomechanics of lumbosacral geometry are unclear, the clinical significance is not, as the lumbosacral junction was found to be associated with low back pain (LBP) [4] and pathological and traumatic conditions [6]. Interestingly, LBP in the adult population constitutes a major health problem $[7,8]$ with debilitating consequences for both the affected individuals and society [9]. The path to a remedy for back pain will involve multidisciplinary cooperation [4] and identification of any predisposing factor would be of benefit to its management [9]. Furthermore, explaining the interactions of sacral base angle (SBA) and lumbar gravity line position (GL) with stability of the lumbosacral junction may lead to understanding of the mechanism of lumbar spondylolisthesis and LBP of mechanical and pathophysiologic origins.

Noteworthy, body mass index (BMI), which is inversely proportional to square of height of an individual is a factor of LBP $[9,10]$. In addition, Baner et al. [2] established a relationship between the height of an object and force of gravity. Furthermore, there are anecdotal reports of some alternative health providers in our locality suggesting that tall people are predisposed to LBP. Given these suggestions 
necessitated studies designed to investigate the contribution of height of a patient to the condition. Hence, any evidence from this work will contribute to the knowledge of the etiology of LBP and close the gap in the literature.

\section{Materials and Methods}

The ethical approval for this study was given by the ethics committee of Enugu State University Teaching Hospital and National Orthopedic Hospital in line with the conditions of the Medical Research Ethics Committee. A total of 488 patients were examined and 358 were excluded because of previous surgery or injury. Informed consent was obtained from the remaining 130 patients (84 with non-injury related LBP and 46 without LBP but other clinical conditions requiring lumbosacral radiography might be present) at the outpatient departments of the above hospitals. Fifty-seven patients were female and 73 were male and the age ranged between 16 and 80 years. Patient height was measured with a Gulfex Medical and Scientific health scale (Model RGZ-120, England) considering their age and sex. Antero-posterior and lateral lumbosacral X-ray images were obtained using computed radiography (digitizer model: 1069301, Care Stream Vita Flex, Israel; Dell LCD Monitor, model E1914H, Ireland). Independently blinded radiological assessments by two consultant radiologists were conducted in each case. Cases without LBP and evidence of degeneration or irregularities were classified as a normal report, while those with positive radiological findings were identified and classified according to clinical conditions. SBA (Ferguson's lumbosacral angle) and GL were determined in all patients as follows:

\section{SBA measurement}

Measurements were conducted using Ferguson's technique. The bottom of the film was employed as the horizontal plane. The angle formed between the base of the sacrum and the horizontal plane was measured with a protractor as the SBA (Figure 1).

\section{Lumbar gravity line measurement}

The lumbar gravity line was determined in the lateral projection by drawing a vertical line perpendicular to the horizontal plane through the center of the third lumbar vertebral body to intersect the sacral base. Consequently, the sacral base was divided into three areas: posterior third $\left(\mathrm{P}^{1 / 3}\right)$, middle third $\left(\mathrm{M}^{1 / 3}\right)$ and anterior third $\left(\mathrm{A}^{1 / 3}\right)$ as shown in Figure 1. Anterior shifts of the gravity line beyond the sacral base were calculated using the magnification of the digital radiograph and assigned to two groups: within $10 \mathrm{~mm}$ anteriorly and more than $10 \mathrm{~mm}$ anteriorly from the sacral base (also adopted by Banks [3]).

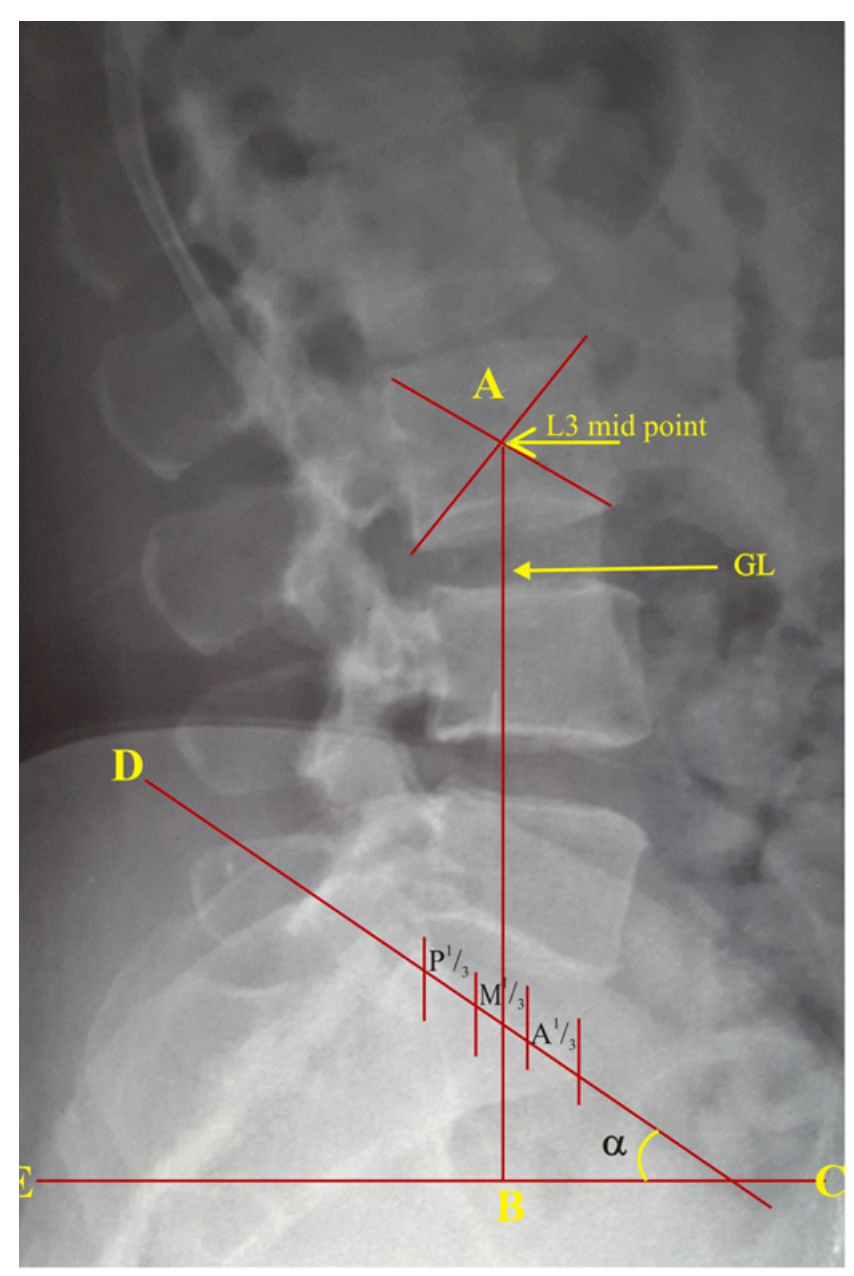

Figure 1. Illustration of sacral base angle and gravity line position measurements, L3-third lumbar, GL-gravity line, $\alpha$-sacral base angle, /CE/-horizontal line parallel to the bottom edge of the film/ CD/-sacral base.

\section{Statistical Analysis}

1. Since residuals cannot be normally distributed, direct regression analysis was performed to assess the direction, magnitude and significance of each predictor and number of factors affecting the likelihood of the following hypotheses:

(i) The patient has LBP according to the model containing four predictors (SBA, GL, sex and age).

(ii) The radiological report will reveal that the patient has spondylolisthesis with the model containing four predictors (SBA, GL, sex and age).

2. Kruskall Walis test was used to show the association between SBA and other grouping variables (Sex, age, height and GL)

3. Pearson's correlation was used to test the hypothesis of dependency between height of the patient and LBP.

The parameters were coded as follows: 
Considering the lumbosacral geometry as a functional matrix predicting the development of spine derangement and low back pain

\section{$\boldsymbol{G L}$}

Posterior third of the sacral base $(\mathrm{P} 1 / 3)=1$

More than $10 \mathrm{~mm}$ anteriorly from the sacral base $(>10 \mathrm{mmA})$ $=2$

Middle third of the sacral base $(\mathrm{M} 1 / 3)=3$

Within $10 \mathrm{~mm}$ anteriorly from the sacral base $(\leq 10 \mathrm{mmA})=4$

Anterior third of the sacral base $(\mathrm{A} 1 / 3)=5$

\section{$\boldsymbol{L B P}$}

Presence of $\mathrm{LBP}=1$, absence of $\mathrm{LBP}=0$

Radiological report

Spondylolisthesis $=1$, other radiological findings $=0$

\section{Sex}

Male $=1$, Female $=0$
Data were analyzed using Kruskal-Wallis test for correlation, logistic and linear regression analyses of IBM SPSS Statistics 22 .

\section{Results}

The model containing four predictors (SBA, gravity line, sex and age) predicted LBP in 84 out of 130 patients, with no statistical significance $[\times 2(\mathrm{df} 4, \mathrm{~N}=130)=6.320, \mathrm{P}<0.05]$. Therefore, the model as a whole was unable to distinguish between patients with and without LBP. The model as a whole explained between 0.047 (Cox and Snell R squared) and 0.065 (Nagelkerke R squared) of the variance in LBP and correctly classified $66.9 \%$ of the cases. According to the results in Table 1, only SBA made a unique statistically significant contribution to the model. With other factors in the model controlled for, the corresponding odds ratio (OR) was 1.045, indicating that for every unit change in SBA the patient was 1.045 times $(4.5 \%)$ more likely to have LBP.

Table 1. Direct logistic regression analysis to predict low back pain with the following parameters.

\begin{tabular}{|c|c|c|c|c|c|c|c|}
\hline \multirow[b]{2}{*}{ Parameters } & \multirow[b]{2}{*}{ B } & \multirow[b]{2}{*}{ S.E. } & \multirow[b]{2}{*}{ Wald } & \multirow[b]{2}{*}{ Sig. } & \multirow[b]{2}{*}{$\operatorname{Exp}(B)$} & \multicolumn{2}{|c|}{$95 \%$ confidence interval for $\operatorname{Exp}(B)$} \\
\hline & & & & & & Lower & Upper \\
\hline GL & 0.117 & 0.134 & 0.755 & 0.385 & 1.124 & 0.864 & 1.463 \\
\hline SBA & 0.044 & 0.019 & 5.233 & 0.022 & 1.045 & 1.006 & 1.086 \\
\hline Sex & -0.025 & 0.383 & 0.004 & 0.947 & 0.975 & 0.46 & 2.066 \\
\hline Age & -0.002 & 0.012 & 0.029 & 0.865 & 0.998 & 0.975 & 1.022 \\
\hline Constant & -1.387 & 1.017 & 1.86 & 0.173 & 0.25 & & \\
\hline
\end{tabular}

Only SBA (odds ratio: $1.045, \mathrm{P}<0.05$ ) was a significant factor predicting the development of LBP

The model containing four predictors (SBA, gravity line, sex and age) successfully distinguished spondylolisthesis from other conditions detected by radiography, including absence of pathology, spondylolysis, infectious spondylitis (TB), straightening of lordosis, scoliosis, rheumatoid arthritis, osteoporosis, vacuum phenomenon and spina bifida occulta $(\times$ $2=25.189, \mathrm{P}<0.05)$. The model explained between 0.176 (Cox and Snell R squared) and 0.345 (Nagelkerke R squared) of the variance in spondylolisthesis and correctly classified $86.2 \%$ of the cases.

Table 2. Direct logistic regression analysis to predict Spondylolisthesis with the following parameters.

\begin{tabular}{|c|c|c|c|c|c|c|c|}
\hline \multirow[b]{2}{*}{ Parameters } & \multirow[b]{2}{*}{ B } & \multirow[b]{2}{*}{ S.E. } & \multirow[b]{2}{*}{ Wald } & \multirow[b]{2}{*}{ Sig. } & \multirow[b]{2}{*}{$\operatorname{Exp}(B)$} & \multicolumn{2}{|c|}{$95 \%$ confidence interval for $\operatorname{Exp}(B)$} \\
\hline & & & & & & Lower & Upper \\
\hline GL & -1.327 & 0.394 & 11.335 & 0.001 & 0.265 & 0.123 & 0.574 \\
\hline SBA & 0.021 & 0.026 & 0.677 & 0.411 & 1.021 & 0.971 & 1.074 \\
\hline Age & 0.014 & 0.021 & 0.457 & 0.499 & 1.014 & 0.973 & 1.057 \\
\hline Sex & 0.67 & 0.663 & 1.02 & 0.313 & 1.954 & 0.532 & 7.17 \\
\hline Constant & -1.283 & 1.569 & 0.669 & 0.413 & 0.277 & & \\
\hline
\end{tabular}

Only $\mathrm{GL}$ (odds ratio: $0.265, \mathrm{P}<0.05$ ) was a significant factor predicting the occurrence of Spondylolisthesis

Only GL made a unique statistically significant contribution to the model $(\mathrm{OR}=0.265)$ (Table 2$)$, indicating that for every unit reduction in the coded value of GL (shift from anterior third) the radiological examination was $73.5 \%$ likely to detect 
spondylolisthesis, with other factors in the model controlled for.

The corresponding logistic regression coefficient (B) of -1.327 indicated an inverse association between GL and spondylolisthesis, suggesting that occurrence of spondylolisthesis was associated with a reduction in the coded value of GL.
The association between SBA and other variables (sex, age, height) was not significant but the test demonstrated a highly significant relationship with GL \{Kruskal-Wallis Test $\left(\chi^{2}=29.192 ; \mathrm{df}=4 ; \mathrm{p}\right.$-value $\left.\left.=0.00 ; \mathrm{p}<0.01\right)\right\}$ as shown in Table 3 .

The regression analysis in Table 4 shows that SBA is predictable using the following equation; $\mathrm{SBA}=50.783-2.662$ GL.

Table 3. Test ${ }^{a}$ of association between SBA and the grouping variables.

\begin{tabular}{lllll}
\hline Variables & Sex & Age & Body height & GL \\
\hline Chi-square & 3.013 & 3.119 & 3.925 \\
\hline Asymp. Sig. & 0.556 & 0.538 & 0.416 & 29.192 \\
\hline
\end{tabular}

${ }^{a} x^{2}=29.192 ; p$-value $\left.=0.00 ; p<0.01\right)$ is associated with SBA.

The negative sign of the correlation coefficient (r) -0.409 indicates an inverse relationship and, given that the highest value of GL (5) in this study corresponded to anterior third of the sacral base, decreases in the coded values of GL correspond to increases in the SBA.

Table 4. Determination of linear relationship between GL and SBA.

\begin{tabular}{|c|c|c|c|c|c|}
\hline \multirow[t]{2}{*}{ Variables } & \multicolumn{3}{|c|}{ Coefficients } & \multirow[t]{2}{*}{$\mathbf{T}$} & \multirow[t]{2}{*}{ Sig } \\
\hline & $\mathbf{B}^{\mathrm{a}}$ & Std error & $\mathbf{B}^{\mathrm{b}}$ & & \\
\hline Constant & 50.783 & 2.836 & & 17.907 & 0.000 \\
\hline GL & -2.662 & 0.731 & -0.409 & -3.643 & 0.001 \\
\hline
\end{tabular}

The regression coefficients of the predictors were highly significant $(P<0.01)$. SBA $=50.783-2.662 \mathrm{GL}, \mathrm{B}^{\mathrm{a}}$ Unstandardized Coefficients, $\mathrm{B}^{\mathrm{b}}$ Standardized Coefficient

The relationship between $\mathrm{LBP}$ and height was statistically insignificant $(\mathrm{P}$ value $=0.078, \mathrm{P}<0.05)$, indicating that occurrence of LBP does not depend on the height of the patient.

\section{Discussion}

A limited number of patients with non-injury related LBP seek conventional medical treatment in outpatient departments in our locality. About $75-90 \%$ of the world population still relies on plants and plant extracts as a source of primary health care [11]. Consequently, most patients that present to hospitals have serious conditions requiring in-patient treatment. Most patients encountered in the outpatient departments during data collection were victims of injury, especially road traffic accidents. In agreement, Giles and Singer [4] reported that the most common cause of mechanical back pain $(72 \%)$ is dysfunction of spinal intervertebral joints due to injury, while lumbar spondylosis accounts for approximately $10 \%$ of such cases. Most patients referred for lumbosacral radiography with a normal radiological report had non-specific back pain or no LBP, but other clinical conditions requiring lumbosacral radiography might be present. Plane radiography of the lumbosacral spine is often performed as part of initial investigation of patients with non-specific and mechanical LBP; painless lumbar compression fractures or fractures with pain referred to the hip, groin, or buttocks; reduced deep tendon reflexes in lower limbs; acute urinary retention with or without LBP; and conus medullaris syndrome [9].

This results suggest that LBP cannot be predicted by age, sex and GL but may be predicted using SBA. The logistic regression coefficient (B) of 0.044 also indicated that the association between SBA and LBP was positive, confirming that a high SBA increased the risk of developing LBP. This agrees with the conclusions of Giles et al. [4] who observed that an increase in SBA, gravity line passing through the posterior one-third of the sacral base and an increase in lumbosacral disc angle were associated with increased incidence of the facet syndrome in patients with LBP. The relatively weak association $(\mathrm{OR}=1.045)$ obtained in this work suggests that an SBA deviating from the normal range within a population should be combined with other known contributory factors to identify non-injury related LBP. Such factors include obesity $[9,12]$, pathology, facet asymmetry and tropism $[4,13]$, physical activity [14], work-related static posture and workload [15].

Secondly, we found that spondylolisthesis cannot be predicted by age, sex, or SBA but can be predicted by GL and that an anterior or posterior shift of GL from the anterior third of the sacral base may result in anterolisthesis or retrolisthesis, respectively. In support of this result, Ergun et al. [16] reported an association between spondylolisthesis and decreased thickness of the transverse process, lumbar angle, sacral table 
angle, sagittal angle of the facet joint and first sacral vertebra inter-facet index. The highly significant association $(\mathrm{OR}=0.265)$ in this study suggests that GL can be utilized by radiologists and chiropractors to detect spondylolisthesis, especially, in cases without any obvious symptoms or where ambiguity is present.

The interaction between GL and SBA reveals that GL on the posterior third of the sacral base was associated with a high value of SBA. In agreement, Adams et al. [17] and Banks [3] observed that a shift in GL from the anterior third of the sacral base may suggest a stress on the lumbosacral facets, particularly the pars interarticularis. In mechanics, the direction and resultant force of two forces acting at an angle depends on the magnitude of the forces and angle it makes with the horizontal plane [18]. If there is an increase in value of the angle, it leads to a reduction in the resultant force. Therefore, it follows that an increase in SBA leads to a reduction in weight transmitted from upper body to the body of sacrum, with a shift of a relatively large amount of weight to the lumbosacral facets. In support of this conclusion, April [19] observed that an approximately $140^{\circ}$ angle normally exists between L5 and the sacral axis, along with a $40^{\circ}$ angle between the $\mathrm{S} 1$ body and the horizontal plane, which increases the force acting on the articulation processes of S1. Moreover, Yochum et al. [20] associated high SBA with LBP and noted that it increases the shearing and compressive forces on the articulation facets of the lumbosacral junction.

Interestingly, this study reveals how a relatively large weight of the upper extremities and trunk could shift from the neural arch to pars interarticularis at the lumbosacral junction because of variations in the SBA and GL. Likewise, Ezemagu et al. [21] noted that a certain amount of weight from the upper extremities and trunk shifts from the anterior column to the posterior column of weight transmission at the lumbosacral junction. Banks [3] suggested an increase in the shearing stress to the lumbosacral facets if the gravity line passes anterior to the sacrum by more than $10 \mathrm{~mm}$. The study demonstrates the clinical accuracy of SBA in determination of non-injury related LBP, especially in cases where ambiguity is present. This may also explain why high values of the SBA were associated with LBP in this study.

Remarkably, Moshirfar et al. [22] stated that the complex local anatomy, unique biomechanical forces and poor bone quality of the sacrum are just a few of the many reasons why fusions of the lumbosacral spine have been difficult to perform. Therefore, variations in the values of the SBA and gravity line position, which are linked to alterations in magnitude and direction of resultant weight transferred from the fifth lumbar vertebra to the sacrum, should be taken into account during reconstructive surgical interventions. This may prevent complications and facilitate postoperative relief for certain spinal geometric distortions and deformities. Thus, during the last decade, vertebral augmentation with cement, kyphoplasty and vertebroplasty $[23,24]$, in conjunction with pedicle screwbased approaches [25-27] have been used for treating severe spinal deformities.
This study demonstrates the significance of SBA and GL in the evaluation of LBP and spondylolisthesis. It reveals that GL can be utilized by radiologists and chiropractors to detect spondylolisthesis. Moreover, SBA can be utilized in combination with other contributory factors to detect LBP of a mechanical or pathophysiologic origin. In practice, this will reduce the number of unnecessary lumbosacral radiographs for non-specific LBP.

Conversely, our results do not support the anecdotal reports that tall people are predisposed to non-injury related LBP, although gravitational potential energy $(\mathrm{Ug}=\mathrm{m} \times \mathrm{g} \times \mathrm{y}$, where $\mathrm{y}=\mathrm{y}_{1}-\mathrm{y}_{0}$ is the height to which the load was lifted from its initial position) depends on mass and height of the object [2]. We noted that occurrence of LBP among the patients is associated with a high BMI; especially in cases of central obesity in our preceding published article. Therefore, the study suggests that occurrence of LBP is not due to the height of a patient, which is a function of BMI but rather to weight of the body. Thus, combination of a high BMI and SBA could be responsible for LBP among the patients. Likewise, authors $[10,27]$ observed that obesity is a strong and independent predictor of recurrent hernia of nucleus pulposus and readmission after lumbar microdiscectomy.

\section{Conclusion}

In summary, SBA and GL are biomechanical parameters that need to be considered in spine derangements, etiology of spondylolisthesis and LBP. This may allow care providers to rapidly select possible treatment strategies and avoid exposing the patient to repeated unnecessary irradiations. Secondly, GL depends on SBA. Thirdly, LBP does not depend on the height of the individual, disproving anecdotal reports that tall people are predisposed to LBP. Finally, lumbosacral geometry should be considered when determining if an individual is fit for professions requiring transfer of large weights at the lumbosacral junction. This may prevent occurrence of LBP in predisposed individuals with poor knowledge of spine kinesiology.

\section{Acknowledgement}

We would like to thank Tertiary Education Trust Fund (Nigeria) for providing fund (2 million naira/\$5500) and Editage (www.editage.com) for English language editing. We thank emeritus professor of plastic surgery and human Anatomy F. C. Akpuaka for his advice, and Dr. Felix Aguboshim and Sylvester Chukwu for the statistical analysis of this work.

\section{References}

1. Johnson K, Johnson A. Physics for you. Nelson Thomas Ltd, UK, 2001.

2. Baner W, Westfall GD. University Physics with Modern Physics. New York Mc Graw-Hill, USA, 2011. 
3. Banks SD. The use of spinographic parameters in the differential diagnosis of lumbar facet and disc syndromes. J Manip Physiol Ther 1983; 6: 113-114.

4. Giles LGF, Singer KP. Clinical anatomy and management of low back pain. Butterworth Heinemann Oxford, UK, 1997.

5. Sowa GA, Coelho JP, Bell KM, Zorn AS, Vo NV, Smolinski P, Niyonkuru C, Hartman R, Studer RK, Kang JD. Alterations in gene expression in response to compression of nucleus Pulposus cells. Spine J 2011; 1: 36-43.

6. Aruna N, Rajeshwari T, Rajangam S. Transmission of weight through the neural arch of lumbar vertebrae in man. J Anatomical society India. 2003; 52: 128-131.

7. Althoff I, Brinckmann P, Frobin W, Sandover J, Burton K. An improved method of stature measurement for quantitative determination of spinal loading. Spine 1992; 17: 682-693.

8. Deyo RA, Tsui-Wu YJ. Descriptive epidemiology of lowback pain and its related medical care in the United States. Spine 1987; 12: 264-268.

9. Ezemagu UK, Anibeze CIP, Ani CO, Ossi GC. Correlation of body mass index with low back pain amongst patients without injury in a Nigeria population. Int J Curr Microbiol App Sci 2016; 5: 371-378.

10. Dennis S, Meredith RC, Huang JN, Stephen LS. Obesity increases the risk of recurrent herniated nucleus pulposus after lumbar microdiscectomy Spine J 2010; 7: 575-580.

11. Benzie IFF, Watchtel-Galor S: In: Herbal Medicine: Biomolecular and Clinical Aspects. 2nd ed, CRC Press, USA 2011; pp 1- 2.

12. Arana E, Kovacs FM, Royuela A, Estremera A, Asenjo B, Sarasíbar H. Modic changes and associated features in Southern European chronic low back pain Patients. Spine J. 2011; 5: 402-411.

13. Ezemagu UK, Anibeze CIP. Sagittal angle and orientation of superior articular facets of the zygapophyseal joints at lumbosacral junction. J Exp Clin Anatomy 2011; 10: 18-20.

14. Zadro JR, Shirley D, Amorim A, Pérez-Riquelme F, Ordoñana JR, Ferreira PH. Are people with chronic low back pain meeting the physical activity guidelines? A cotwin control study. Spine J 2017; 6: 845-854.

15. Egwu AO, Ewunonu EO, Eteudo AN, Ovuoba KN, Ugwu AC, Akpa AOC. Prevalence of neck upper back and chest musculoskeletal symptoms among medical students in Ebonyi State. J Exp Clin Anatomy 2006; 5: 41-43.

16. Ergun T, Sahin MS, Lakadamyali H. Two- and threedimensional reformatted computed tomography imaging analysis of lumbosacropelvic structure in degenerative anterolisthesis. Clin Radiol 2011; 65: 908-915.
17. Adams MA, Hutton WC. The effect of posture on the role of the joints in resisting intervertebral compressive force. $\mathrm{J}$ Bone Joint Surg Br 1980; 62: 358-362.

18. Beiser A. Applied Physics. 2nd ed, Tata Mc Gaw-Hill, New Delhi, India. 2007.

19. April E. Clinical anatomy. Williams \& Wilkins, New York, USA, 1997.

20. Yochum TR, Rowe LJ. Essentials of Skeletal Radiology. Williams \& Wilkins, Baltimore, USA, 1987.

21. Ezemagu UK, Anibeze CP, Akpuaka CF. Considering the inferior surface area of lower lumbar vertebrae: Determining weight transmission pattern at the lumbosacral junction. Anat Sci Int 2018; 93: 277-283.

22. Moshirfar A, Rand FF, Sponseller PD, Parazin SJ, Khanna AJ, Kebaish KM, Stinson JT, Riley LH. Pelvic fixation in spine surgery: Historical overview, indications, biomechanical relevance and current techniques. J Bone Joint Surg Am 2005; 87: 89-106.

23. Limthongkul W, Karaikovic EE, Savage JW, Markovic A. Volumetric analysis of thoracic and lumbar vertebral bodies. Spine J 2010; 2: 153-158.

24. Mai HT, Mitchell SM, Hashmi SZ, Jenkins TJ, Patel AA, Hsu WK. Differences in bone mineral density of fixation points between lumbar cortical and traditional pedicle screws. Spine J 2016; 7: 835-841.

25. Ponnusamy KE, Iyer S, Gupta G, Khanna AJ. Instrumentation of the osteoporotic spine: Biomechanical and clinical considerations. Spine J 2011; 1: 54-63.

26. Janssen I, Ryang YM, Gempt J, Bette S, Gerhardt J, Kirschke JS, Meyer B. Risk of cement leakage and pulmonary embolism by bone cement-augmented pedicle screw fixation of the thoracolumbar spine. Spine J 2017; 6: 837-844.

27. Cheng CW, Cizik AM, Dagal AHC, Lewis L, Lynch J, Bellabarba C, Bransford RJ, Zhou H. Body mass index and the risk of deep surgical site infection following posterior cervical instrumented fusion. Spine J 2019; 4: 602-609.

\section{*Correspondence to}

Uchenna Kenneth Ezemagu

Department of Anatomy

Alex Ekwueme Federal University Ndufu Alike Ikwo

Abakaliki, Ebonyi

Nigeria 